\title{
Primary care clinicians perceptions about antibiotic prescribing for acute bronchitis: a qualitative study
}

\author{
Patrick P Dempsey ${ }^{1}$, Alexandra C Businger ${ }^{1}$, Lauren E Whaley ${ }^{2}$, Joshua J Gagne ${ }^{3}$ and Jeffrey A Linder ${ }^{1,4^{*}}$
}

\begin{abstract}
Background: Clinicians prescribe antibiotics to over $65 \%$ of adults with acute bronchitis despite guidelines stating that antibiotics are not indicated.

Methods: To identify and understand primary care clinician perceptions about antibiotic prescribing for acute bronchitis, we conducted semi-structured interviews with 13 primary care clinicians in Boston, Massachusetts and used thematic content analysis.

Results: All the participants agreed with guidelines that antibiotics are not indicated for acute bronchitis and felt that clinicians other than themselves were responsible for overprescribing. Barriers to guideline adherence included 6 themes: (1) perceived patient demand, which was the main barrier, although some clinicians perceived a recent decrease; (2) lack of accountability for antibiotic prescribing; (3) saving time and money; (4) other clinicians misconceptions about acute bronchitis; (5) diagnostic uncertainty; and (6) clinician dissatisfaction in failing to meet patient expectations. Strategies to decrease inappropriate antibiotic prescribing included 5 themes: (1) patient educational materials; (2) quality reporting; (3) clinical decision support; (4) use of an over-the-counter prescription pad; and (5) pre-visit triage and education by nurses to prevent visits.

Conclusions: Clinicians continued to cite patient demand as the main reason for antibiotic prescribing for acute bronchitis, though some clinicians perceived a recent decrease. Clinicians felt that other clinicians were responsible for inappropriate antibiotic prescribing and that better pre-visit triage by nurses could prevent visits and change patients expectations.
\end{abstract}

Keywords: Bronchitis, Respiratory tract infections, Anti-bacterial agents, Primary health care, Qualitative research

\section{Background}

Acute bronchitis is a cough-predominant upper respiratory illness, lasting less than three weeks, in a patient without underlying cardiopulmonary disease [1]. National guidelines and performance measures, based on randomized controlled trials and meta-analyses, recommend avoiding antibiotic prescribing for patients with acute cough/acute bronchitis [2-5]. Over the past several decades, the Centers for Disease Control and Prevention and other organizations have continued efforts to discourage

\footnotetext{
*Correspondence: jlinder@partners.org

1 Division of General Medicine and Primary Care, Brigham and Women s Hospital, 1620 Tremont Street, Boston, MA 02120, USA

${ }^{4}$ Harvard Medical School, Boston, MA, USA

Full list of author information is available at the end of the article
}

antibiotic prescribing for acute bronchitis [6]. Despite these efforts, physicians in the United States prescribe antibiotics in over $65 \%$ of acute cough/acute bronchitis visits $[7,8]$. Unnecessary antibiotic prescriptions provide no clinical improvement, expose patients to the risk of adverse drug events, increase the prevalence of antibiotic-resistant bacteria, and increase healthcare costs [9].

Prior studies have assessed clinicians understanding and attitudes towards antibiotic prescribing for acute bronchitis and other respiratory infections. Most of these studies, summarized in two recent systematic reviews, were performed outside the United States or were published over a decade ago $[10,11]$.

In order to understand contemporary reasons for antibiotic prescribing for acute bronchitis in the United 
States, clinicians familiarity with the clinical guidelines for acute bronchitis, barriers to guideline adherence, and clinicians views on potential solutions for unnecessary antibiotic prescribing, we conducted semi-structured, qualitative interviews with primary care clinicians.

\section{Methods}

\section{Setting and participants}

Thirteen primary care clinicians 12 medical doctors and 1 nurse practitioner were recruited from 3 Brigham and Womens Primary Care Practice-Based Research Network-clinics in Boston. The clinics consisted of 1 hospital-based practice and 2 urban community health centers with approximately 175 clinicians which all serve a socioeconomically, racially, and ethnically diverse patient population. Clinicians were recruited via emails sent by study staff to practice medical directors of the 3 clinics who, in turn, forwarded the request to primary care clinicians. If clinicians expressed interest in participating, study staff contacted the clinicians and obtained consent to participate. Interviews took place during March 2011. Clinicians were internal medicine physicians or internal medicine nurse practitioners, $69 \%$ female, with a mean age of 43 , and an average of 14 years of experience. Clinicians received US $\$ 20$ for their participation. The Brigham and Womens Human Research Committee approved the study protocol.

\section{Interview guide development}

The interview guide was developed as part of an iterative process between our team and a consulting Ph.D.-level, qualitative researcher with extensive training and 12 years of research experience in mixed methods design, field methods, and analysis. We used conceptual models of guideline adherence [12] and appropriate antibiotic prescribing [13] to develop the interview guide, ensuring that a range of concepts would be included. The guide focused on the following goals and domains (Appendix 1):

1. Understand clinicians contemporary views on acute bronchitis guidelines and antibiotic prescribing;

2. Identify what clinicians felt were the main barriers to antibiotic guideline adherence;

3. Seek clinicians ideas and suggestions for methods of improvement for the management of acute bronchitis, clinic workflow, and patient education materials.

\section{Interview conduct}

Interviews were conducted by a medical anthropologist with a Masters Degree in Applied Socio-Cultural Anthropology and 17 years experience in conducting qualitative research interviews. Interviews were completed over the phone and lasted between 30 and 60 minutes. The interviewer obtained IRB-approved verbal informed consent to conduct and record the interview as well as use the content of the interview for analysis and publication. The interviewer generally followed the interview guide, asked open-ended questions, but also improvised questions to elicit additional responses or clarify prior responses. If the participant did not offer solutions for domain 3, the interviewer mentioned specific potential interventions included in the interview guide. We conducted 13 interviews to collect general assessments of attitudes regarding acute bronchitis, reasons for antibiotic prescribing, and solutions to reduce antibiotic prescribing for acute bronchitis. Preliminary analysis of the interviews suggested we were approaching thematic saturation after 12 interviews.

\section{Data collection and analysis}

Each interview was recorded, transcribed verbatim, and analyzed according to a conventional comprehensive qualitative analysis method [14-17]. We used a two-stage coding process: structural coding (Level 1) and thematic coding (Level 2). Structural coding followed the structure of the interview guide: every question received a structural code that was applied to the appropriate text. Thematic coding was based on themes that arose from the structural coding, and was applied in a second-pass analysis. Thematic analysis was inductive and followed the structure of the interview. The thematic content analysis was at the question level, such that themes emerged from the questions. We resolved differences in interpretation through discussion. We used NVivo (Version 8, QSR International) to code, categorize, search, retrieve, attach analytical memos and create conceptual relationship networks in our textual data that had been taxonomically coded. Once the 2 -stage coding process was completed and reviewed by the entire research team, we generated a comprehensive thematic analysis summary report, including exemplary quotes. The analysis was performed and the summary report was written and delivered by the same experienced qualitative researcher that completed the interviews.

In this manuscript, we organized themes by decreasing number of participants who discussed each theme. While this provides quantitative impression of the frequency with which participants discussed each theme, we do not mean to imply that themes with a higher number of discussants are necessarily more important.

\section{Results}

Twelve themes emerged from the data within the 3 interview guide domains. Within the first domain, contemporary views on acute bronchitis guidelines and antibiotic prescribing, there was only 1 consistent theme. Within the second domain, barriers to guideline adherence, there were 6 themes. Within the third domain, methods to reduce antibiotic prescribing, there were 5 themes (Table 1). 
Table 1 Domains and themes regarding antibiotic prescribing for acute bronchitis

\begin{tabular}{|c|c|}
\hline Domain & Theme \\
\hline $\begin{array}{l}\text { Contemporary views on acute } \\
\text { bronchitis guidelines and } \\
\text { antibiotic prescribing }\end{array}$ & $\begin{array}{l}\text { 1. Antibiotics are not indicated } \\
\text { for acute bronchitis, but antibiotics } \\
\text { are overprescribed }\end{array}$ \\
\hline \multirow[t]{6}{*}{ Barriers to guideline adherence } & $\begin{array}{l}\text { 1. Perceived patient demand for } \\
\text { antibiotics }\end{array}$ \\
\hline & $\begin{array}{l}\text { 2. Lack of accountability or feedback } \\
\text { about prescribing }\end{array}$ \\
\hline & 3. Time and money \\
\hline & $\begin{array}{l}\text { 4. Other clinicians misconceptions } \\
\text { about acute bronchitis }\end{array}$ \\
\hline & $\begin{array}{l}\text { 5. Diagnostic uncertainty and } \\
\text { defensive practice }\end{array}$ \\
\hline & $\begin{array}{l}\text { 6. Clinician dissatisfaction with not } \\
\text { meeting patient expectations }\end{array}$ \\
\hline \multirow[t]{5}{*}{$\begin{array}{l}\text { Methods to reduce antibiotic } \\
\text { prescribing }\end{array}$} & $\begin{array}{l}\text { 1. Patient handouts and other } \\
\text { educational materials }\end{array}$ \\
\hline & 2. Quality reports \\
\hline & 3. Clinical decision support \\
\hline & 4. Pre-visit triage by nurses \\
\hline & 5. Over-the-counter prescription pad \\
\hline
\end{tabular}

\section{Domain 1: Contemporary views on acute bronchitis} guidelines and antibiotic prescribing

The consistent theme that emerged regarding guidelines and antibiotic prescribing for acute bronchitis was that all participants agreed with guidelines stating that antibiotics are not indicated for acute bronchitis and clinicians felt like antibiotics for acute bronchitis were overprescribed by other clinicians, but not by themselves. One participant stated the guidelines were,

fantastic, cause I think there IS a lot of unnecessary prescribing for colds, for bronchitis, for viral illnesses. So I think that having a guideline might also be helpful in terms of communicating that to patients, and explaining, you know, Not only do I feel this way, but this is a guideline set up for us by the people in charge of treating . (AB013-MD)

Well established guidelines allowed clinicians to avoid prescribing antibiotics by having an authoritative norm that states antibiotics are not necessary. Despite the availability of guidelines, clinicians felt that other clinicians overused antibiotics.

\section{Domain 2: Barriers to guideline adherence} Perceived patient demand for antibiotics (12 participants) All but one participant cited patient demand as a reason for prescribing antibiotics for acute bronchitis. Responses were similar among participants, commonly referring to the clinic visit being the logical next step after the patient has tried everything else:

I think the patients expectation by the time theyve come to you, they feel they ve tried everything else and they want antibiotics, so thats a big driver. (AB002-MD)

One other participant attributed this to living,

in an instant gratification society, and I think [patients] have the impression that an antibiotic is the thing that ll clear it up really quickly. (AB003-MD)

Another clinician stated,

I don t blame them; I blame us. They re used to it, so, they feel like they bother to come in, so we should deliver. (AB007-MD)

Clinicians felt their patients come to the clinic as a final option, expecting the clinician to provide a quick solution.

Two clinicians mentioned serving patients from cultures where antibiotics are over-the-counter and frequently used:

Most of my patients are Spanish-speaking; most of them are from other cultures. You know, antibiotics are available over the counter, most places that they live. You can get em over the counter, down at the little bodega, down at the corner People go get it, you can buy ampicillin there. You know, and people are used to taking antibiotics all the time, for everything . (AB013-MD)

Differing cultural norms lead clinicians to feel that certain populations have an even greater expectation of receiving antibiotics.

Six clinicians indicated patient demand had decreased over the last 5 years:

I think its much lower than it used to be. I think people kind of get it, at least for colds. I think for bronchitis, they still think a bit differently about bronchitis than they do about colds, and so if we use the word bronchitis, they are a bit more set up to expect antibiotics. But, I would say most people are fairly accepting of the fact that these things are caused by viruses, and they don $t$ respond to antibiotics. So, I would say, you know a fairly significant majority are okay with that. (AB010-MD)

Clinicians perceived that public desire for antibiotics for acute bronchitis has decreased. Clinicians attributed this to the public developing a better understanding of 
the nature of viruses and antibiotics, but still associated the diagnosis bronchitis with a need for an antibiotic.

\section{Lack of accountability or feedback about prescribing (10)}

Eight participants stated that there was no accountability, oversight, or feedback for prescribing antibiotics that they were aware of.

I don think I would NOTICE the difference, really, if I prescribe antibiotics or not I don thave any kind of quality measures that so far I ve had to I haven $t$ really had anyone say anything about it to me .

(AB011-MD)

Two participants felt no direct accountability except from their own conscience and their responsibility to the public to not contribute to increases in the prevalence of antibiotic-resistant bacteria. One said,

I think we re accountable to the public, to not render certain antibiotics powerless, because were contributing to the development of resistant organisms . (AB005-MD)

\section{Time and money (7)}

Seven participants acknowledged financial and time-saving incentives that encourage antibiotic prescribing. One participant said that,

if you do it, you can see more patients, because you end the visit quicker instead of having a long discussion, trying to get their buy-in to not prescribe. So, actually, yes, in essence [there are time and financial incentives]; but not in the we-get-paid-to-use-this-drug-stuff-[way] . (AB007-MD)

Participants felt that simply prescribing an antibiotic rather than educating the patient meant they could end each encounter faster, see more patients, and be more financially productive. All clinicians who cited time or money as a reason for antibiotic prescribing said that they, themselves, do not do this.

Other clinicians misconceptions about acute bronchitis (6) Clinicians felt some of their colleagues did not understand acute bronchitis or were stuck in the habit of prescribing antibiotics for acute bronchitis. Three participants stated that some doctors either do not know or do not believe that acute bronchitis is viral. One participant felt,

many physicians believe that many of the bronchitises are caused by bacterial infections especially when the sputum is green, which is not really true . (AB002-MD)
Another clinician stated that it is more common amongst,

doctors that have been practicing for a long time, its sort of what they ve always done. And so, changing behavior is always harder. Its what they ve always done and what they ve seen their colleagues do, and what their patients have asked them to do. And I think changing those behaviors is very challenging . (AB001-MD)

Two participants stated that some clinicians might believe antibiotics are the correct treatment:

I expect there might be some physicians who actually believe that its helpful. Not putting myself in that category. But that they believe that its the right treatment. (AB004-MD)

Lastly, one participant felt some clinicians perceive antibiotics as harmless:

I think the other thing that probably misinformation on physicians part is that I think a lot of and Im guilty of this, too. I think we think they re kind of harmless. whats the worst that happens if a person was on a course of antibiotics and, they didn $t$ need it? (AB008-MD)

Participants felt there were three main reasons other clinicians prescribed antibiotics for acute bronchitis: thinking that acute bronchitis is caused by bacteria; the fixed behavior of antibiotic prescribing; and thinking that antibiotic prescribing for acute bronchitis is benign.

\section{Diagnostic uncertainty and defensive practice (4)}

Four participants stated that diagnostic uncertainty influenced their decision to prescribe antibiotics. One clinician stated,

the physician can never be $100 \%$ sure its not a bacterial infection, so they worry about that. So theres some clinical uncertainty . (AB002-MD)

Another participant elaborated on practicing defensively:

The guidelines, even though I think they re wellknown, theres certainly variation in uptake around the fact that for those kind of question mark calls, people practice defensively and might want to just be on the safe side, give someone antibiotics, even though its not clear to me that that actually the safer choice to do . (AB012-MD) 
Participants felt that despite well-established guidelines to avoid antibiotic prescribing for acute bronchitis, there will always be some diagnostic uncertainty and associated risk of undertreating an infection when they do not prescribing antibiotics.

\section{Clinician dissatisfaction in not meeting patient expectations (3)}

Three participants discussed antibiotic prescribing as a response to clinician dissatisfaction in failing to meet perceived patient expectations. One clinician stated,

a person who has taken off work come in to urgent care, and then for me to turn em around and say,

Keep doin what you re already doing, I think in some ways doesn $t$ feel very satisfying as a physician .

(AB003-MD)

Another clinician stated,

if somebody is sick enough to come in they re expecting something I think doctors like to do something. You don t like to think there is nothing you can do, and theres nothing you can offer . (AB005-MD)

Clinicians felt that once a patient makes the effort to come into the clinic it is unsatisfying to not be able to offer a solution.

Domain 3: Methods to reduce inappropriate prescribing Patient handouts and other educational materials (13)

All clinicians felt it would be helpful to have educational materials for patients that describe the importance of avoiding unnecessary antibiotic use. The majority of responses stated educational materials would be really helpful (AB008-MD) and would impact prescribing in a huge way (AB011-MD). Three clinicians felt educational posters are or would be useful in addition to handouts:

I think it would be great [I have] the one that says, Antibiotics don $t$ work for colds and flu. Got that right next to where my head is, so people, when they re looking at me, they see the thing saying, Antibiotics are not for you . (AB009-MD)

Clinicians felt that handouts and posters could make for an efficient, established, official-looking means to educate patients about why antibiotics are not needed for acute bronchitis.

One clinician felt that mass media coverage of the issue would be more useful than handouts:

Im always hesitant to hit with handouts and pamphlets I don t think that people really pay attention to that they re already kind of in the office. And if they re in the office, you can just have the conversation The only way people read about things related to their health is they re picking up magazines, like Self, or Cosmo, or Health, or, reading The [Boston] Globe, reading The Metro, so maybe just putting those kind of informational type pieces, in mass media could help . (AB003-MD)

Participants felt that mass media coverage of the issue would be more useful than posters and handouts given in the clinic because they are more attention-getting and have the potential to prevent visits in the first place.

\section{Quality reports (10)}

Ten clinicians felt quality and feedback reports and reviews would be helpful. One clinician stated,

that everyone should get their [upper respiratory infection] dashboard and they should be compared to all their peers in their clinic in their system and that it should be publicly available to patients and supervisors . (AB012-MD)

Two clinicians thought group feedback would be useful:

[it would be] good at the clinic, then you don t sort of demonize somebody, and you get to have the education as a group of clinicians in the clinic . (AB008-MD)

One clinician recommended the pharmacy track prescribing:

I know the pharmacy people track what we prescribe specifically, whether its generic or name brand they track these measures and so they could track who[is] prescribing antibiotics Having evidence, like the number of times that you prescribed antibiotics; these are the cases where you did it . (AB013-MD)

Participants responded that ongoing comparison to their peers and pharmacy tracking could provide ongoing encouragement in lowering antibiotic prescribing rates for acute bronchitis.

\section{Clinical decision support (8)}

Six participants recommended prompts against antibiotics through clinical decision support within the electronic health record. One specifically mentioned an earlier documentation-based clinical decision support prototype:

When we had [an earlier form of electronic clinical decision support], that made it really easy, in my opinion, to be able to more easily flow through these 
visits because it had these prompts that were a little reminder not only did it have the reminders, but then it had all the kind of symptomatic treatment stuff that you could just print out with a click of a button, like, give them the cough syrup and the Tylenol and the this and the that and the patient handouts on it I really liked that form, and I wish it hadn t gone away . (AB012-MD)

Two clinicians recommended that the system have clinicians click an indication which reviews the antibiotic order before being accepted, both comparing it to the way radiology ordering is done. Participants indicated that clinical decision support had been and could be a useful tool to reduce inappropriate antibiotic prescribing for acute bronchitis. Having an established means of reviewing best practices, receiving alternative prescription options, and ready-to-print patient information packets had been useful in the past.

\section{Pre-visit triage and education by nurses (6)}

Six clinicians suggested having nurses Registered Nurses or Licensed Practical Nurses perform pre-visit triage to reduce unnecessary visits. One clinician stated:

I think a lot of people who have respiratory infections automatically think they need to see a doctor because they think they need a prescription. And really good education from the nurses on triage, I think, could actually do a good job of not even bothering to bring these people in . (AB001-MD)

Another clinician added,

there has to be some way of identifying those patients so that you don $t$ bring them in to the clinic, because I think that theres a message in bringing somebody into the clinic that were actually going to do something that you couldn t do at home. (AB005-MD)

Clinicians expressed that having nurses perform previsit triage would be very useful in reducing inappropriate prescribing. Once a patient has made the trip to the clinic it is far more difficult to convince them to simply continue doing the same things. Clinicians thought review and confirmation by triage nurses that the patient was already taking the right steps and did not need to come into the clinic could reduce visits and antibiotic prescribing.

However, three clinicians recommended caution and a potential unintended consequence of pre-visit triage.

You don $t$ want people to feel like they re getting prejudged as not sick, because then they re going to come in even more defensive about BEING sick I $m$ not sure Id want somebody that sort of primed to think theyre not going to get antibiotics, because they re going to get more geared up . (AB007-MD)

\section{Over the counter prescription pad (2)}

Over-the-counter prescription pads are official-looking, pre-printed forms on which clinicians can quickly recommend non-antibiotic, non-prescription remedies to patients. Two participants endorsed using an over-thecounter prescription pad.

I like having the over-the-counter medication kind of prescription pad because one nice thing about it is, it shows the different classes of medications. Like, I think people say, Oh, I just took the cold stuff, but they don t really know the difference between a pain reliever and a decongestant, and an antibiotic and kind of understanding, well, Did what you picked out, match what your complaints and symptoms are? (AB003-MD)

The second clinician used the over-the-counter prescription pad to put the encounter,

in a positive light. You can spin things anyway, Well, the really good news is, you don t actually need to take an antibiotic. Your body can fight this off, we can help it, you know, with these ways . (AB005-MD)

The over-the-counter prescription pad provides an established, official-looking means to do something for the patient without having to prescribe antibiotics.

\section{Discussion}

We conducted qualitative, semi-structured interviews of primary care clinicians to learn about clinicians understanding about acute bronchitis guidelines, barriers to guideline adherence, and thoughts about interventions to decrease antibiotic prescribing for acute bronchitis.

All clinicians agreed with guidelines that antibiotics are not indicated for acute bronchitis. Clinicians perceived that patients continued to have a high level of demand for antibiotics, which remained the largest perceived driver of antibiotic prescribing for acute cough/ acute bronchitis. Clinicians wanted to justify patients efforts and feel satisfied that they are meeting patients expectations. A novel finding was that clinicians noted less demand for antibiotics and better patient understanding in the past five years.

Clinicians generally viewed the problem of antibiotic prescribing for acute bronchitis and solutions 
to address the problem as being someone else s responsibility. Participants felt that other clinicians, especially older clinicians, think antibiotics are harmless. Participants mentioned that better pre-visit triage by nurses to identify patients who do not need to make a visit would save patients money, avoid the inconvenience of an unnecessary visit, and decrease overall antibiotic prescribing. Participants generally did not say that clinicians could do a better job coaching and educating patients themselves.

\section{Comparison with prior qualitative studies}

Prior qualitative studies of clinicians attitudes towards antibiotic prescribing for respiratory infections were mainly done in Europe or in the United States over 10 years ago. Two recent systematic reviews identified 45 individual studies that examined clinicians views of antibiotic prescribing for respiratory infections $[10,11]$. Only 3 reviewed studies examined prescribing for respiratory infections in the United States in the past decade [18-20]. Mangione-Smith and colleagues found that physicians incorrectly perceive patient questioning about whether or not they need antibiotics as indicating a desire for antibiotics, when in fact questioning was not associated with patient desire for antibiotics [18]. Ong and colleagues found that physicians correctly identified only $27 \%$ of patients who wanted antibiotics, but that physician perception of patient desire for antibiotics was the main driver of antibiotic prescribing [19]. Hart and colleagues found that physicians try to balance their own individual best practice with perceived patient satisfaction by using education, negotiation, holding-firm, or giving-in [20].

Not included in the systematic reviews, was one newer qualitative study by Ackerman and colleagues [21]. Ackerman and colleagues, as part of a randomized controlled trial of print and electronic-delivered decision support to encourage judicious antibiotic prescribing, found improved awareness of antibiotic resistance, but clinicians still cited patient expectations, time pressure, and diagnostic uncertainty as barriers to judicious antibiotic prescribing [22].

Some of the many qualitative studies from Europe highlight similar themes from our study and other studies regarding antibiotic prescribing for acute cough. These studies describe non-medical reasons for antibiotic prescribing such as the physician having previously missed a diagnosis of pneumonia in a different patient, patient expectations, and maintaining patient satisfaction [23-26]. European studies describe clinical reasons for prescribing antibiotics such as diagnostic uncertainty, fear of making an error of omission (i.e., not prescribing an antibiotic when it was indicated), and reliance on certain clinical factors like lung findings, fever, shortness of breath, sputum production, or crackles $[26,27]$. One multinational European study by BrookesHowell and colleagues highlighted international variations in guidelines, systems to reduce patients expectation for antibiotics, and availability of antibiotics without a prescription [25]. Recently, a study by Mustafa and colleagues found that Welsh primary care physicians, rather than directly asking about patient desire for antibiotics, preferred to use a running commentary during the physical examination reviewing findings and implications with the patient as they are examined to reassure, share information, and strategically educate to set patient expectations that an antibiotic prescription was not necessary without appearing curt or dismissive $[18,28,29]$.

\section{Limitations}

Our qualitative study has several limitations. First, clinicians were academically-affiliated and those who agreed to participate may have a particular interest in judicious antibiotic prescribing or be less likely to prescribe antibiotics. Second, participants may have been constrained by the content of the interview guide or given socially desirable answers. However, to avoid topic constraint or social desirability, the interviewer asked openended questions and encouraged participants to speak broadly. Third, our sample size was relatively small. However, the low number of emergent themes suggests we approached thematic saturation. Fourth, many of the themes discussed were about participants views on other clinicians attitudes and behavior, which may or may not reflect other clinicians actual attitudes and behavior.

\section{Implications for clinical practice and practice improvement}

If the patient has an acute cough, is not immunosuppressed, does not have a concomitant alternative diagnosis, has normal vital signs and a normal lung exam, antibiotics are not indicated [1]. Despite clinicians perception that patients are only interested in antibiotics, other studies have shown that clinicians overestimate this desire and poorly predict which patients want antibiotics $[19,30,31]$. Clinicians should be educated that antibiotic prescribing is, at most, marginally associated with patient satisfaction [19,31-33]. Future guidelines should address the role of explicit and perceived patient demand in antibiotic prescribing.

Ongoing education and patient-directed materials such as handouts, posters, and over-the-counter prescription pads may further decrease perceived patient demand for antibiotics [34]. Outside of clinic visits, as suggested by our study, improved quality reports although prior studies about monitoring and feedback are conflicting [35-37] and pre-visit interventions should continue to be evaluated to decrease inappropriate antibiotic 
prescribing for acute bronchitis [38]. Accurate point of care tests, which were not addressed in our study, might be acceptable to clinicians and patients $[39,40]$.

Clinicians should feel secure in their decision that antibiotics are not indicated, should not assume patients want antibiotics, and consider using the running commentary method to educate and reassure as they do the physical examination $[28,29,41]$. Additionally, as our participants pointed out and as previously described, clinicians might consider using a term other than acute bronchitis, like a chest cold, which is accurate, but less associated with patient expectation for antibiotics $[42,43]$. Rather than focusing on antibiotics, clinicians should focus on symptomatic treatment and educating patients at the time of the visit about realistic expectations for the duration of cough, which lasts, on average, three weeks $[18,44]$.

\section{Conclusions}

In our qualitative study to understand contemporary attitudes regarding acute bronchitis in the United States, we found that clinicians agreed with antibiotic prescribing guidelines for acute bronchitis, felt that patient demand remained the main driver of antibiotic prescribing, but that demand may have lessened recently. Clinicians discussed a range of solutions to decrease antibiotic prescribing. Many of the solutions discussed were done by someone other than the treating clinician, like nurses doing better pre-visit triage and education, or behind the scenes solutions, such as clinical decision support and feedback. However, clinicians will continue to address patients with acute bronchitis and are an integral part of implementing solutions to decrease inappropriate antibiotic prescribing.

\section{Appendix 1}

Interview guide summary

Questions for Clinicians Understanding of Antibiotic Treatment for Acute Cough in Primary Care

\section{Guidelines for antibiotic prescribing}

1. Do you have any insight into why antibiotics are overprescribed for acute bronchitis?

2. What do you think of the guidelines?

3. What has your experience been in following the guidelines? How rigid or flexible do you feel they are?

4. Is there any accountability for following or not following them?

5. Are there any financial incentives for or against prescribing antibiotics?

6. Are there instances in which clinicians bend the guidelines?

\section{Clinicians perception of patient desire and demand for antibiotics}

1. What do clinicians perceive as patients level of desire for and demand for antibiotics?

2. What steps could clinicians at the clinic level take to reduce the over prescribing of antibiotics?

\section{Clinic workflow}

1. Can you think of ways that the clinic workflow could be changed to reduce the prescribing rate of antibiotics?

a) For example, could changes be made before, during, or after the patient visit?

Let me offer a couple of other suggestions for you to discuss as potential solutions

1. Clinician decision support

2. Quality reports

3. Patient education

\section{Review of draft education materials}

1. What do you think of Additional file 1?

2. What do you think of Additional file 2?

3. What suggestions do you have for improving Additional file 1?

4. What suggestions do you have for improving Additional file 2?

5. Would it be appropriate to educate patients as part of the counseling about the importance of not taking too many antibiotics?

\section{Final section}

1. How do you feel about having a patient handout to give to patients at the end of a visit that details the symptomatic treatment for cough?

\section{Additional files}

Additional file 1: Clinician Handout for Patients.

Additional file 2: The Centers for Disease Control and Prevention Get Smart Owl.

\section{Competing interests}

The authors declare that they have no competing interests.

\section{Authors contributions}

PPD, ACB, and LEW participated in study design, development of the interview guide, study coordination, data analysis, and drafting of the manuscript. JJG conducted the interviews and the initial data analysis. JAL conceived of the study, supervised all aspects of the study, and drafted the manuscript. All authors read and approved the final manuscript. 


\section{Acknowledgements}

The authors thank Katherine Taylor Haynes (KTH), PhD for her expertise in developing the interview guide.

\section{Support}

This project was funded by the Agency for Healthcare Research and Quality (R18 HS018419).

\section{Author details}

'Division of General Medicine and Primary Care, Brigham and Women s Hospital, 1620 Tremont Street, Boston, MA 02120, USA. ²Bureau of Infectious Diseases, Massachusetts Department of Public Health, Boston, MA, USA. ${ }^{3}$ Survey and Data Management Core, Dana Farber Cancer Institute, Boston, MA, USA. ${ }^{4}$ Harvard Medical School, Boston, MA, USA.

Received: 20 August 2014 Accepted: 12 November 2014 Published online: 12 December 2014

\section{References}

1. Snow V, Mottur-Pilson C, Gonzales R: Principles of appropriate antibiotic use for treatment of acute bronchitis in adults. Ann Intern Med 2001, 134(6):518 520.

2. Gonzales R, Bartlett JG, Besser RE, Cooper RJ, Hickner JM, Hoffman JR, Sande MA: Principles of appropriate antibiotic use for treatment of uncomplicated acute bronchitis: background. Ann Intern Med 2001, 134(6):521 529

3. Irwin RS, Baumann MH, Bolser DC, Boulet LP, Braman SS, Brightling CE, Brown KK, Canning BJ, Chang AB, Dicpinigaitis PV, Eccles R, Glomb WB, Goldstein LB, Graham LM, Hargreave FE, Kvale PA, Lewis SZ, McCool FD, McCrory DC, Prakash UB, Pratter MR, Rosen MJ, Schulman E, Shannon JJ, Smith Hammond C, Tarlo SM: Diagnosis and management of cough executive summary: ACCP evidence-based clinical practice guidelines. Chest 2006, 129(1 Suppl):1S 23S.

4. National Committee for Quality Assurance. HEDIS 2012 Measures. http://www.ncqa.org/HEDISQualityMeasurement/HEDISMeasures/HEDIS2012. aspx. Accessed October 7, 2014

5. Smith SM, Fahey T, Smucny J, Becker LA: Antibiotics for acute bronchitis. Cochrane Database Syst Rev 2014, (3):Art. No.: CD000245. doi:10.1002/ 14651858.CD000245.pub3.

6. Centers for Disease Control and Prevention. Get Smart: Know When Antibiotics Work. http://www.cdc.gov/getsmart/. Accessed October 7, 2014.

7. Grijalva CG, Nuorti JP, Griffin MR: Antibiotic prescription rates for acute respiratory tract infections in US ambulatory settings. JAMA 2009, 302(7):758 766.

8. Barnett $M L$, Linder $J A$ : Antibiotic prescribing for adults with acute bronchitis in the United States, 1996 2010. JAMA 2014, 311(19):2020 2022.

9. Centers for Disease Control and Prevention: Antibiotic Resistance Threats in the United States, 2013. ; 2013. http://www.cdc.gov/drugresistance/threatreport-2013/. Accessed August 25, 2014

10. Tonkin-Crine S, Yardley L, Little P: Antibiotic prescribing for acute respiratory tract infections in primary care: a systematic review and meta-ethnography. J Antimicrob Chemother 2011, 66(10):2215 2223.

11. Teixeira Rodrigues A, Roque F, Falcao A, Figueiras A, Herdeiro MT: Understanding physician antibiotic prescribing behaviour: a systematic review of qualitative studies. Int J Antimicrob Agents 2013, 41(3):203 212.

12. Cabana MD, Rand CS, Powe NR, Wu AW, Wilson MH, Abboud P-AC, Rubin HR: Why don t physicians follow clinical practice guidelines? A framework for improvement. JAMA 1999, 282(15):1458 1465.

13. Ranji SR, Steinman MA, Shojania KG, Sundaram V, Lewis R, Arnold S, Gonzales R: Antibiotic Prescribing Behavior. Closing the Quality Gap: a Critical Analysis of Quality Improvement Strategies. Technical Review 9 (Prepared by the Stanford University-UCSF Evidence-based Practice Center under Contract No. 290-02-0017), AHRQ Publication No 04(06)-0051-4. Rockville, MD: Agency for Healthcare Research and Quality; 2006.

14. Hsieh HF, Shannon SE: Three approaches to qualitative content analysis. Qual Health Res 2005, 15(9):1277 1288.

15. Kondracki NL, Wellman NS, Amundson DR: Content analysis: review of methods and their applications in nutrition education. $J$ Nutr Educ Behav 2002, 34(4):224 230
16. Miles MB, Huberman AM: Qualitative Data Analysis: an Expanded Sourcebook. 2nd edition. Thousand Oaks, CA: Sage; 1994.

17. Morse JM, Field PA: Qualitative Research Methods for Health Professionals. 2nd edition. Thousand Oaks, CA: Sage; 1995.

18. Mangione-Smith R, Elliott MN, Stivers T, McDonald LL, Heritage J: Ruling out the need for antibiotics: are we sending the right message? Arch Pediatr Adolesc Med 2006, 160(9):945 952.

19. Ong S, Nakase J, Moran GJ, Karras DJ, Kuehnert MJ, Talan DA: Antibiotic use for emergency department patients with upper respiratory infections: prescribing practices, patient expectations, and patient satisfaction. Ann Emerg Med 2007, 50(3):213 220.

20. Hart AM, Pepper GA, Gonzales R: Balancing acts: deciding for or against antibiotics in acute respiratory infections. J Fam Pract 2006, 55(4):320 325.

21. Gonzales R, Anderer T, McCulloch CE, Maselli JH, Bloom FJ, Graf TR, Stahl M, Yefko M, Molecavage J, Metlay JP: A cluster randomized trial of decision support strategies for reducing antibiotic use in acute bronchitis. JAMA Intern Med 2013, 173(4):267 273.

22. Ackerman SL, Gonzales R, Stahl MS, Metlay JP: One size does not fit all: evaluating an intervention to reduce antibiotic prescribing for acute bronchitis. BMC Health Serv Res 2013, 13:462.

23. Coenen S, Van Royen P, Vermeire E, Hermann I, Denekens J: Antibiotics for coughing in general practice: a qualitative decision analysis. Fam Pract 2000, 17(5):380 385

24. Butler CC, Rollnick S, Pill R, Maggs-Rapport F, Stott N: Understanding the culture of prescribing: qualitative study of general practitioners and patients perceptions of antibiotics for sore throats. BMJ 1998, 317(7159):637 642

25. Brookes-Howell L, Hood K, Cooper L, Little P, Verheij T, Coenen S, GodyckiCwirko M, Melbye H, Borras-Santos A, Worby P, Jakobsen K, Goossens $H_{\text {, }}$ Butler CC: Understanding variation in primary medical care: a ninecountry qualitative study of clinicians accounts of the non-clinical factors that shape antibiotic prescribing decisions for lower respiratory tract infection. BMJ Open 2012, 2(4):e000796.

26. Coenen S, Michiels B, Van Royen P, Van der Auwera JC, Denekens J: Antibiotics for coughing in general practice: a questionnaire study to quantify and condense the reasons for prescribing. BMC Fam Pract 2002, 3:16.

27. Brookes-Howell L, Hood K, Cooper L, Coenen S, Little P, Verheij T, GodyckiCwirko M, Melbye H, Krawczyk J, Borras-Santos A, Jakobsen K, Worby P, Goossens $H$, Butler CC: Clinical influences on antibiotic prescribing decisions for lower respiratory tract infection: a nine country qualitative study of variation in care. BMJ Open 2012, 2(3):e000795.

28. Mustafa M, Wood F, Butler CC, Elwyn G: Managing expectations of antibiotics for upper respiratory tract infections: a qualitative study. Ann Fam Med 2014 12(1):29 36.

29. Heritage J, Elliott MN, Stivers T, Richardson A, Mangione-Smith R: Reducing inappropriate antibiotics prescribing: the role of online commentary on physical examination findings. Patient Educ Couns 2010, 81(1):119 125.

30. Linder JA, Singer DE: Desire for antibiotics and antibiotic prescribing for adults with upper respiratory tract infections. J Gen Intern Med 2003, 18(10):795 801

31. Brookes-Howell L, Hood K, Cooper L, Coenen S, Little P, Verheij T, GodyckiCwirko M, Melbye H, Krawczyk J, Borras-Santos A, Jakobsen K, Worby P, Goossens H, Butler CC: Are patient views about antibiotics related to clinician perceptions, management and outcome? A multi-country study in outpatients with acute cough. PLOS ONE 2013, 8(10):e76691.

32. Hamm RM, Hicks RJ, Bemben DA: Antibiotics and respiratory infections: are patients more satisfied when expectations are met? J Fam Pract 1996, 43(1):56 62

33. Ray DA, Rohren $\mathrm{CH}$ : Characteristics of patients with upper respiratory tract infection presenting to a walk-in clinic. Mayo Clin Proc 2001, 76(2):169 173

34. Meeker D, Knight TK, Friedberg MW, Linder JA, Goldstein NJ, Fox CR, Rothfeld A, Diaz G, Doctor JN: Nudging guideline-concordant antibiotic prescribing: a randomized clinical trial. JAMA Intern Med 2014, 174(3):425 431.

35. Linder JA, Schnipper UL, Tsurikova R, Yu DT, Volk LA, Melnikas AJ, Palchuk MB, Olsha-Yehiav M, Middleton B: Electronic health record feedback to improve antibiotic prescribing for acute respiratory infections. Am J Manag Care 2010, 16(12 Suppl HIT):e311 e319.

36. Litvin CB, Ornstein SM, Wessell AM, Nemeth LS, Nietert PJ: Use of an electronic health record clinical decision support tool to improve 
antibiotic prescribing for acute respiratory infections: the ABX-TRIP study. J Gen Intern Med 2012, 28(6):810 816.

37. Litvin CB, Ornstein SM, Wessell AM, Nemeth LS, Nietert PJ: Adoption of a clinical decision support system to promote judicious use of antibiotics for acute respiratory infections in primary care. Int J Med Inform 2012, 81(8):521 526.

38. Persell SD, Friedberg MW, Meeker D, Linder JA, Fox CR, Goldstein NJ, Shah PD, Knight TK, Doctor JN: Use of behavioral economics and social psychology to improve treatment of acute respiratory infections (BEARI): rationale and design of a cluster randomized controlled trial [1RC4AG039115 01] study protocol and baseline practice and provider characteristics. BMC Infect Dis 2013, 13:290.

39. Wood F, Brookes-Howell L, Hood K, Cooper L, Verheij T, Goossens H, Little P, Godycki-Cwirko M, Adriaenssens N, Jakobsen K, Butler CC: A multi-country qualitative study of clinicians and patients views on point of care tests for lower respiratory tract infection. Fam Pract 2011, 28(6):661 669.

40. Tonkin-Crine S, Yardley L, Coenen S, Fernandez-Vandellos P, Krawczyk J, Touboul P, Verheij T, Little P: GPs views in five European countries of interventions to promote prudent antibiotic use. Br J Gen Pract 2011, 61(586):e252 e261.

41. Mangione-Smith R, Stivers T, Elliott M, McDonald L, Heritage J: Online commentary during the physical examination: a communication tool for avoiding inappropriate antibiotic prescribing? Soc Sci Med 2003, 56(2):313 320.

42. Phillips TG, Hickner J: Calling acute bronchitis a chest cold may improve patient satisfaction with appropriate antibiotic use. J Am Board Fam Pract 2005, 18(6):459 463.

43. Gonzales R, Wilson A, Crane LA, Barrett PH Jr: Whats in a name? Public knowledge, attitudes, and experiences with antibiotic use for acute bronchitis. Am J Med 2000, 108(1):83 85.

44. Ebell MH, Lundgren J, Youngpairoj S: How long does a cough last? Comparing patients expectations with data from a systematic review of the literature. Ann Fam Med 2013, 11(1):5 13.

doi:10.1186/s12875-014-0194-5

Cite this article as: Dempsey et al:: Primary care clinicians perceptions about antibiotic prescribing for acute bronchitis: a qualitative study. BMC Family Practice 2014 15:194.

\section{Submit your next manuscript to BioMed Central and take full advantage of:}

$\nabla$ Convenient online submission

$\otimes$ Thorough peer review

$\otimes$ No space constraints or color $₫$ gure charges

$\triangle$ Immediate publication on acceptance

$\triangle$ Inclusion in PubMed, CAS, Scopus and Google Scholar

$\nabla$ Research which is freely available for redistribution 